\title{
Factors influencing the distribution of large mammals within a protected central African forest
}

\author{
Allard Blom, Robert van Zalinge, Ignas M.A. Heitkönig and Herbert H.T. Prins
}

\begin{abstract}
This paper presents the analyses of data obtained from eight permanent $20 \mathrm{~km}$ transects to determine the relative effect of local human populations and ecological factors on the distribution of large mammals within the Dzanga sector of the Dzanga-Ndoki National Park and the adjacent area of the Dzanga-Sangha Dense Forest Special Reserve in south-west Central African Republic. Principal component analysis indicated that human activities significantly influence the distribution of large mammals, even within this protected area. Distance from the village and the main road as well as
\end{abstract}

the distance from secondary roads appeared to have the greatest influence. Elephants in particular were significantly less common in areas related to human use. Our study showed that poachers use roads, both primary and secondary, to penetrate into the National Park. Thus increasing anti-poaching efforts along these roads could be an effective protection measure.

Keywords Central African Republic, Dzanga-Sangha, hunting, mammals, monitoring, protected areas.

\section{Introduction}

The impacts of humans on the density and distribution of elephants in Central Africa is well known (Barnes et al., 1997), and there is a similar relationship for other species (Noss 1995, 1998; Lahm et al., 1998; Blom, 2001). The effect of human disturbance varies greatly, depending on its nature and intensity, and understanding this interaction is essential for managing protected areas (Prins \& Reitsma, 1989; White, 1994; Fitzgibbon et al., 1995; Oates, 1996; Hall et al., 1998). However, large mammal densities and distribution are also influenced by a range of ecological factors, including vegetation (Barnes et al., 1991; White, 1994).

The objective of this study was to determine the relative effect of local human populations and ecological factors on the density and distribution of wildlife within the Dzanga sector of the Dzanga-Ndoki National Park and the adjacent area of the Dzanga-Sangha Dense Forest Special Reserve, part of the Dzanga-Sangha Protected Area Complex, in the Central African Republic (Fig. 1). By looking at the distribution of human activities and vegetation as well as a range of species our aim was to obtain a better understanding of how vegetation and

\footnotetext{
Allard Blom* (Corresponding author), Robert van Zalinge, Ignas M. A. Heitkönig and Herbert H.T. Prins Resource Ecology Group, Wageningen University, Bornsesteeg 69, 6708 PD, Wagenigen, The Netherlands.

E-mail allard.blom@wwfus.org

${ }^{*}$ Current address: World Wildlife Fund, $125024^{\text {th }}$ Street NW, Washington, DC, USA. Also at: Dzanga-Sangha Project, World Wildlife Fund, B.P. 1053, Bangui, Central African Republic.
}

Received 27 October 2003. Revision requested 27 May 2004. Accepted 17 December 2004 human activities influenced mammal distributions. This study is a follow-up to earlier research that looked at densities of elephants and apes (Blom et al., 2001; A. Almaši, unpubl. data) using line transects. It is part of an ongoing effort in the Dzanga-Sangha Protected Area Complex to monitor the density and distribution of wildlife for research purposes and management, both directly (e.g. by removing snares) and indirectly by guiding adaptive management.

\section{Study area}

The Dzanga-Sangha Protected Area Complex (Fig. 1) consists of sectors of the Dzanga-Ndoki National Park (Dzanga sector $495 \mathrm{~km}^{2}$; Ndoki sector $727 \mathrm{~km}^{2}$ ) and the Dzanga-Sangha Dense Forest Special Reserve $\left(3,159 \mathrm{~km}^{2}\right)$. The Reserve, within which the sustainable use of natural resources is allowed, functions as a buffer zone for the National Park (Carroll, 1992).

One hundred and five species of non-flying mammals have been observed within the Dzanga-Sangha area (Blom, 1993), including elephant Loxodonta africana cyclotis, chimpanzee Pan troglodytes troglodytes and western lowland gorilla Gorilla gorilla gorilla, as well as nine species of monkey and six species of duiker. The area is renowned for its high densities of gorilla and forest elephant (Carroll, 1986a,b,c, 1988a,b, 1997; Fay, 1989, 1991a,b, 1997; Blom et al., 2001; A. Almaši, A. Blom, K. Otto, J-B. Kpanou \& H.H.T. Prins, unpubl. data). Hunting is legal within the Reserve, but is currently being practised at unsustainable levels for at least three species of duiker (Cephalophus callipygus, C. dorsalis and C. monticola; Noss, 1998). 


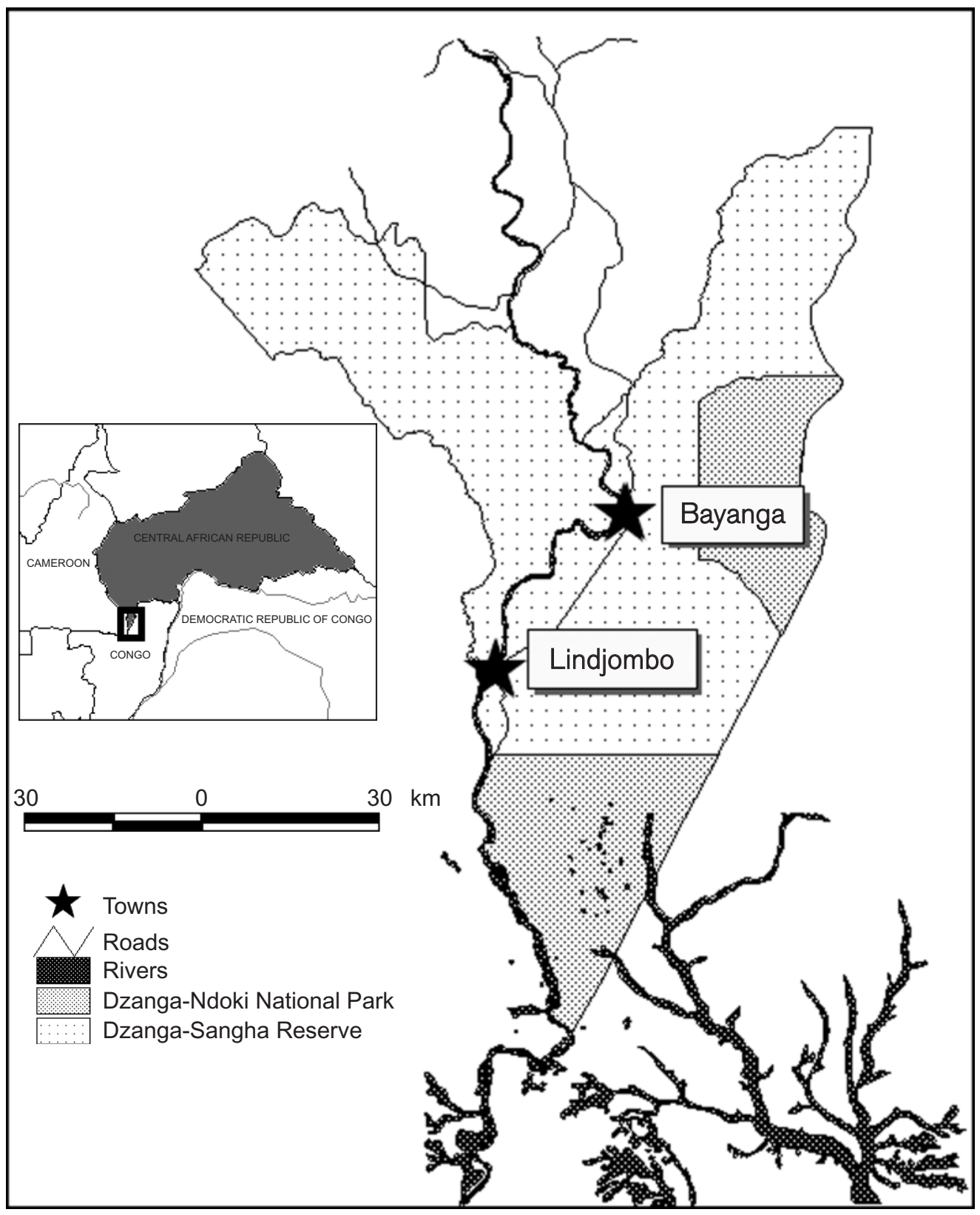

Fig. 1 Dzanga-Sangha Protected Area Complex, consisting of the Dzanga-Ndoki National Park (with the Dzanga and Ndoki sectors in the north and south, respectively) and the Dzanga-Sangha Dense Forest Special Reserve, with the location of the two main villages. The rectangle on the inset indicates the location of the main figure in the Central African Republic.

The human population density in this area is low at c. 1 person $\mathrm{km}^{-2}$, and c. $60 \%$ of people live in the town of Bayanga (2,365 inhabitants in 1995; Gonda Ngbalet, 1995; Blom, 2001). The rest of the population, c. 2,400 people, mostly live along the road from the northern limit of the Reserve to Lindjombo (720 inhabitants), the second largest settlement in the Reserve (Fig. 1). The BaAka pygmies comprise the largest ethnic group in the area and, like most other people there, are dependent on wildlife as a source of daily protein.

Most of the survey and monitoring presented in this study was undertaken in and adjacent to the Dzanga sector (Fig. 2), which was selectively logged in the 1970s and early 1980s. The forest is a combination of large tracts of primary forest, interspaced with single-species stands of Gilbertiodendron dewevreii, and secondary forest with 


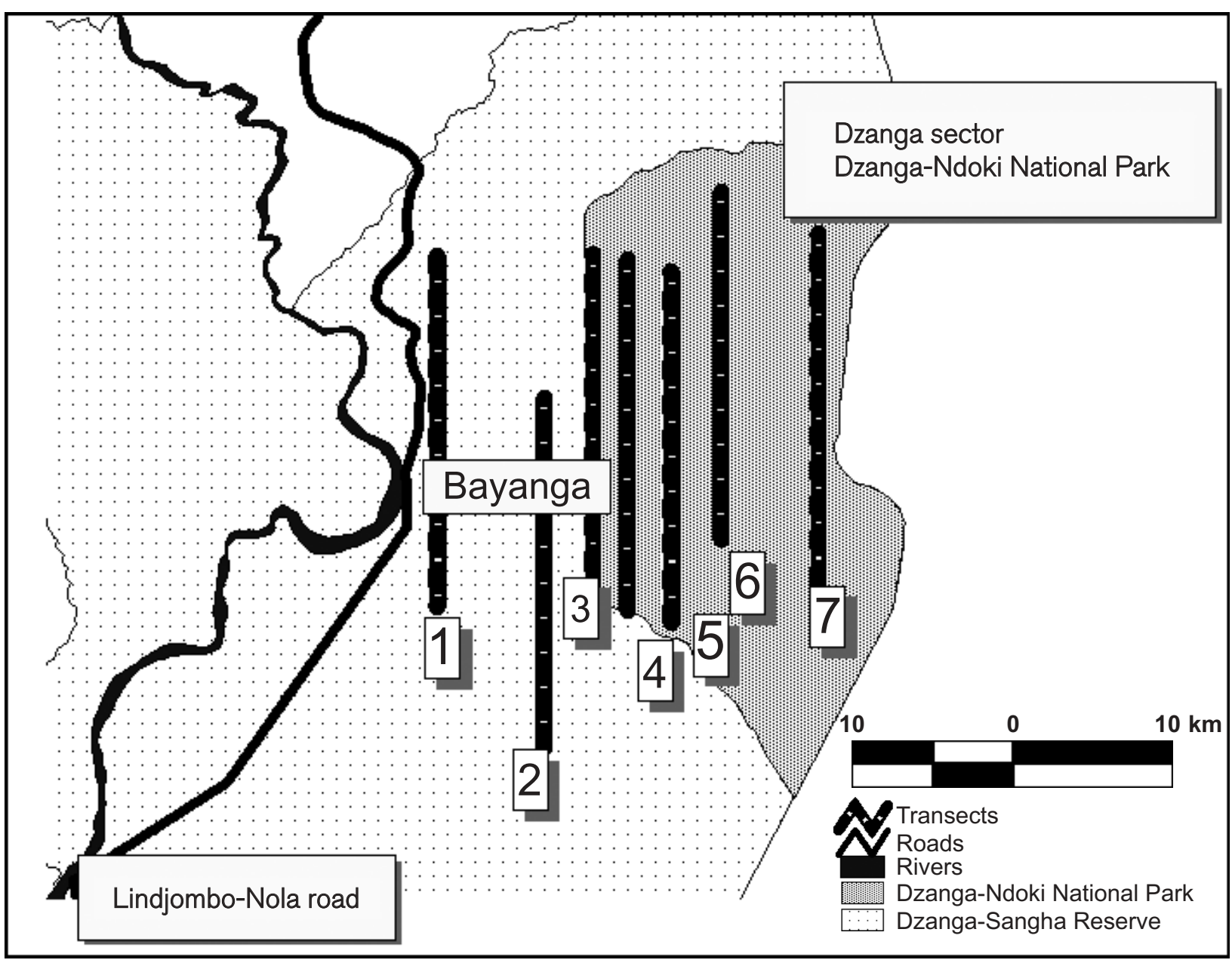

Fig. 2 The Dzanga sector of the Dzanga-Ndoki National Park, with transect 1 and 2 in the Dzanga-Sangha Dense Forest Special Reserve to the west, transects 3-7 in the Park, and transect 3 running along the western boundary of the Park.

large quantities of herbaceous undergrowth and light gaps (A. Almaši, A. Blom, K. Otto, J-B. Kpanou \& H.H.T. Prins, unpubl. data). The mean annual rainfall is $1,365 \mathrm{~mm}$, with a dry season from December to February (Carroll, 1997).

\section{Methods}

This study took place from April to June 1998. Prior to the start seven $20 \mathrm{~km}$ transects were randomly placed perpendicular to a base line that ran east - west through Bayanga and parallel to the main road and starting at a road or a river (Blom et al., 2001). Six transects were in the Dzanga sector, one on the western boundary of the Park, and two in the Reserve between the main road and the Park (Fig. 2). The transects were perpendicular to drainage flow and thus included much of the variation in habitat. Each transect was walked at an even pace once per month by at least one researcher and two BaAka pygmy trackers. All snares and cartridges found were removed.
Each transect was subdivided into $500 \mathrm{~m}$ sections. Distances from the centre point of each transect to the main Nola-Lindjombo road and of each $500 \mathrm{~m}$ section to the nearest secondary logging road were measured using satellite photos. The percentages of the different habitat types found in each block were determined during the initial placement of the transects (A. Almaši, A. Blom, K. Otto, J-B. Kpanou \& H.H.T. Prins, unpubl. data). During the monthly surveys the observers noted the occurrence of the following signs from the transect line: elephant dung piles, ape nests, species of monkey (seen or heard) and apes (feeding remains, traces/tracks, seen or heard) and human presence and type of presence (snare, cartridge, net, tree cut, opened beehive, footprints, camps and trails). For all variables the sample level was the transect section.

Data on duiker were collected by dung counts along strip transects. A strip transect $1 \mathrm{~km}$ long and $3 \mathrm{~m}$ wide was located on each transect within a mixed forest type of uniform structural appearance. All strip transects 
were placed by the same person. Average pace along these strips was c. $0.5 \mathrm{~km} \mathrm{hr}^{-1}$. Two individuals would search for duiker dung while the other(s) carried out the other observations. We distinguished dung as belonging to either red duikers (Cephalophus callipygus, C. dorsalis, C. leucogaster and C. nigrifrons) or the smaller blue duiker Cephalophus monticola. Dung of the larger yellow-backed duiker C. sylvicultor was only rarely encountered, and was not therefore included in our analysis. Only one duiker survey could be carried out, along the Park boundary and in the Reserve, in June 1998.

Besides leaving feeding remains of plants, lowland gorillas frequently feed on termites (Tutin \& Fernandez, 1984, 1992; Carroll, 1997), leaving characteristic traces, and they tend to eat different species than chimpanzees (Tutin \& Fernandez, 1992). Traces of chimpanzees other then nest sites were rarely encountered and therefore not included in our analysis.

Five habitat types were distinguished (Blom, 2001): mixed forest, Gilbertiodendron forest, disturbed forest, light gaps, and waterlogged and exposed habitats. Even though there are probably seasonal variations in the distribution of mammal species, the influence of this on our analysis was limited as the data were collected over a 3-month period.

We used SPSS 8.0 (SPSS, 1997) for analysis. Tests were either one-tailed or two-tailed depending on the hypothesis, with a $5 \%$ level of significance. We used CANOCO 3.15 (ter Braak, 1987-1992) to carry out a principal components analysis (PCA) to examine the association of mammalian traces with vegetation characteristics and human activities recorded on the transects. The PCA was applied to the animal species data set (species' traces per $500 \mathrm{~m}$ section of transect). The variables in the environmental data set (forest type and human traces per $500 \mathrm{~m}$ section) were correlated a posteriori with each of the principal component axes. Principal component analysis transforms a number of potentially correlated variables into a smaller number of uncorrelated components, the first of which accounts for as much variability in the data as possible, followed by the second and subsequent components. Using the first two components this technique provides an ordination of mammalian species in a two-dimensional plane, onto which both vegetation and human activity variables can be plotted (Kent \& Coker, 1994). In our study the biplot indicates which of the forest and human activity variables correlate strongest with the variation in mammalian abundance.

Subsequently multiple linear regression was used to select the environmental variables that explain the greatest variation in species abundance. The assumptions are that the dependent variable is normally distributed around any given value of the independent variables and that the variance around the regression line is constant (Sokal \& Rohlf, 1995). To test for a normal distribution we used the Kolmogorov-Smirnov test on the residuals from the regression. Where regression could not be applied, Spearman's rank correlation test was used. We tested for differences between sectors in the mean encounter rates per transect using the Mann-Whitney U-test.

\section{Results}

For most species the mean encounter rate was highest in the Dzanga sector, followed by the Park boundary, and

Table 1 Mean encounter rates of species per $\mathrm{km}$ in the three sectors of the Dzanga-Sangha Complex (Fig. 1), and the statistical comparisons of differences.

\begin{tabular}{|c|c|c|c|c|c|c|}
\hline \multirow[b]{2}{*}{ Species $(\operatorname{sign})^{1}$} & \multicolumn{3}{|c|}{ Mean encounter rates per km } & \multicolumn{3}{|c|}{$\begin{array}{l}Z \text { statistic of differences between } \\
\text { sectors }^{2}\end{array}$} \\
\hline & $\begin{array}{l}\text { Dzanga-sector } \\
\text { (Ds) }\end{array}$ & $\begin{array}{l}\text { Park boundary } \\
(\mathrm{Pb})\end{array}$ & $\begin{array}{l}\text { Reserve } \\
\text { (R) }\end{array}$ & Ds vs $\mathrm{Pb}$ & Ds vs $\mathrm{R}$ & $\mathrm{Pb}$ vs $\mathrm{R}$ \\
\hline Putty-nosed monkey Cercopithecus nictitans & 0.30 & 0.18 & 0.18 & $-2.23^{*}$ & $-2.46^{*}$ & -0.10 \\
\hline Moustached Monkey Cercopithecus cephus & 0.08 & 0.06 & 0.05 & -0.65 & -1.37 & -0.29 \\
\hline Crowned monkey Cercopithecus pogonias & 0.16 & 0.05 & 0.06 & $-2.19^{*}$ & $-2.18^{*}$ & -0.30 \\
\hline Grey-cheeked mangabey Lophocebus albigena & 0.25 & 0.05 & 0.03 & $-2.61^{* *}$ & $-2.99^{* * *}$ & -0.32 \\
\hline Agile mangabey Cercocebus agilis & 0.05 & 0.03 & 0.02 & -0.59 & -1.58 & -1.07 \\
\hline Gorilla Gorilla gorilla gorilla $(\mathrm{t})$ & 0.88 & 0.31 & 0.18 & -1.95 & $-2.87^{* *}$ & -0.56 \\
\hline Gorilla (n) & 0.04 & 0.02 & 0.01 & -0.42 & -1.18 & -0.83 \\
\hline Chimpanzeé Pan troglodytes troglodytes (n) & 0.04 & 0.05 & 0.02 & -0.50 & -0.84 & -0.27 \\
\hline Elephant Loxodanta africana cyclotis (d) & 16.32 & 5.67 & 2.43 & $-3.16^{* * *}$ & $-3.37^{* * *}$ & $-2.20^{*}$ \\
\hline Blue duiker Cephalophus monticola (d) & 0.15 & 0.05 & 0.05 & -1.33 & -1.33 & 0.00 \\
\hline Red duiker Cephalophus spp. (d) & 0.19 & 0.00 & 0.00 & -1.61 & -1.61 & 0.00 \\
\hline All duikers (d) & 0.17 & 0.03 & 0.03 & $-2.12^{*}$ & $-2.12^{*}$ & 0.00 \\
\hline
\end{tabular}

${ }^{1} \mathrm{t}$, trace; $\mathrm{n}$, nests; $\mathrm{d}$, dung piles

${ }^{2 *} \mathrm{P}<0.05,{ }^{* *} \mathrm{P}<0.01,{ }^{* * *} \mathrm{P}<0.005$ 


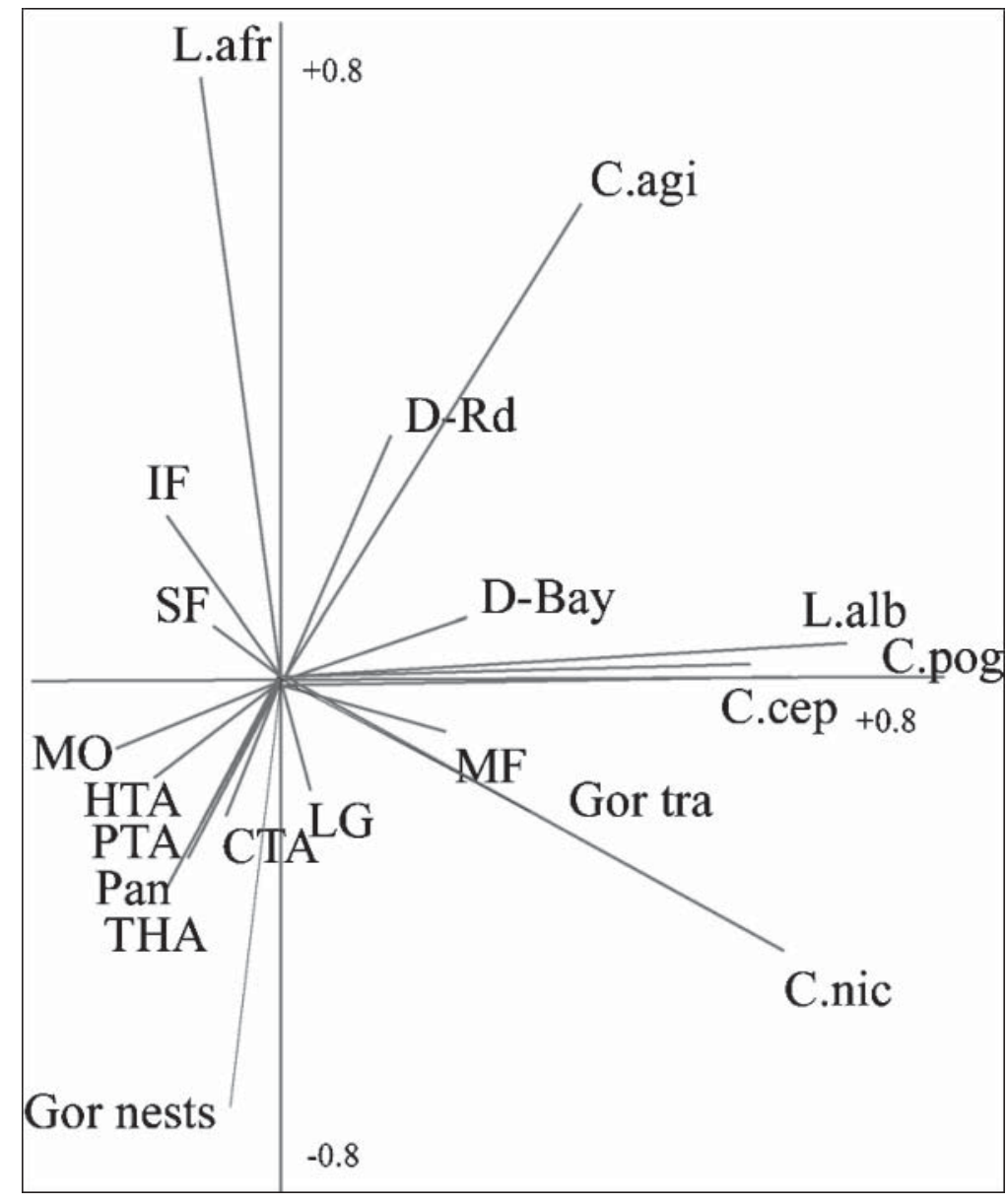

Fig. 3 Biplot of principal component analysis (see text for details) of the distribution of mammal species corelated with environmental variables. L.afr, L. africana cyclotis; Gor tra, traces of G. g. gorilla; Gor nests, gorilla nests; Pan, P. t. troglodytes nests; L.alb, L. albigena; C.agi, C. agilis; C.nic, C. nictitans; C.cep, Cercopithecus cepus; C.pog, C. pogonias (all encounter rates); D-Rd, Distance from roads; D-Bay, Distance from village; HTA, Hunting trace; CTA, Collection trace; PTA, Passage trace; THA, Total human trace (all encounter rates); MF, Mixed forest; MO, Gilbertiodendron forest; LG, Light gaps; SF, Disturbed forest; IF, Waterlogged and exposed habitats. lowest in the Reserve (Table 1). The only exceptions were crowned monkey Cercopithecus pogonias, for which the encounter rate along the Park boundary was slightly lower than in the Reserve, and chimpanzees, for which the encounter rate on the Park boundary was slightly higher than in the Dzanga sector. There were no significant differences in encounter rates between areas for red and blue duikers separately, but when combined the differences between the Park and other sectors were significant.

Only the first and second principal components are illustrated in the biplot (Fig. 3) as they have the highest correlations with most species. The relative length of a line is a measure of the strength of the relationship between that variable and the axis. All species of monkey have a strong correlation with the first axis, which is positively associated with increasing distance along the main road from the village of Bayanga and mixed forest, and negatively associated with Gilbertiodendron forest. Forest elephants and agile mangabeys Cercocebus agilis are correlated with the second axis, which is positively associated with distance from secondary roads and waterlogged and exposed forest, but negatively associated with human disturbance. Gorilla abundance was best correlated with the third axis, which was positively associated with mixed forest and distance from Bayanga, and negatively associated with distance from secondary roads.

Applying the Kolmogorov-Smirnoff test showed that the residual variation from regression of species mean encounter rates against most of the environmental variables did not have a normal distribution. By taking the natural logarithm of the mean encounter rates, regression was possible for putty-nosed monkeys Cercopithecus nictitans, gorillas, elephants and grey-cheeked mangabeys Lophocebus albigena. Transformed mean encounter rate for grey-cheeked mangabeys was not significantly correlated with any environmental variable. Putty-nosed monkeys were significantly more abundant further away from Bayanga and outside blocks where waterlogged and exposed habitats were strongly represented $\left(R^{2}=0.18, \mathrm{P}<0.01\right)$. Gorilla traces were more frequently found in blocks further from Bayanga and with relatively more mixed forest $\left(R^{2}=0.15, \mathrm{P}<0.01\right)$. Elephant dung 
Table 2 Environmental variables that were significantly correlated $(\mathrm{P}<0.05)$ with mean species encounter rates, arranged by order of magnitude of the correlation coefficient.

\begin{tabular}{|c|c|}
\hline Species $^{1}$ & Environmental variables (direction of significant correlation) ${ }^{2}$ \\
\hline Putty-nosed monkey & Waterlogged and exposed habitats $(-)$; mixed forest $(+)$; village $(-)$ \\
\hline Moustached monkey & Secondary roads $(-)$ \\
\hline Crowned monkey & Village $(-)$ \\
\hline Grey-cheeked mangabey & Village $(-)$; secondary roads $(-)$; hunting trace $(-)$; human trace $(-)$ \\
\hline Agile mangabey & Secondary roads $(-)$ \\
\hline Gorilla $(t)$ & Waterlogged and exposed habitats $(-)$; mixed forest $(+)$; village $(-)$; monodominant forest $(-)$ \\
\hline Gorilla (n) & Light gap $(+)$; collection trace $(+)$ \\
\hline Chimpanzee (n) & None \\
\hline Elephant (d) & Secondary roads $(-)$; village $(-)$; human trace $(-)$; passage trace $(-)$; hunting trace $(-)$; collection trace $(-)$ \\
\hline Blue duiker (d) & None $\quad$ l \\
\hline Red duikers (d) & Mixed forest $(+)$; secondary roads $(-)$ \\
\hline
\end{tabular}

${ }^{1} \mathrm{t}$, trace; $\mathrm{n}$, nests; $\mathrm{d}$, dung piles

${ }^{2}(+)$ or $(-)$ signs indicate the direction of the relationship

abundance was strongly related to increasing distance from Bayanga and blocks that had a lower occurrence of human traces $\left(R^{2}=0.39, \mathrm{P}<0.01\right)$. There were no correlations with chimpanzees and blue duikers. Table 2 shows those environmental variables that were significantly correlated with species' mean encounter rates.

\section{Discussion}

The data show a significant difference between the Park and Reserve in the encounter rates for elephant, gorilla traces, duikers and three of the five species of monkeys. This could be related to habitat differences, as a correlation analysis of environmental variables, such as habitat and distance from village, found that monocultures of Gilbertiodendron were most frequently encountered nearer to Bayanga, whereas the disturbed forest was found further from Bayanga (Blom, 2001). However the fact that for most species the mean encounter rate is highest in the Dzanga sector followed by the Park boundary, and lowest in the Reserve, indicates that this is a general trend and probably not related to habitat, as the requirement for all these species is likely to be different.

The presence of several species is negatively correlated with distance from secondary roads. This is probably not related to habitat differences as such roads are present throughout the area surveyed. In our original design of the monitoring programme we had underestimated the influence of these roads. Based on this research the ongoing monitoring programme was recently redesigned and extended to cover the remaining area of the complex (D. Greer, pers. comm., June 2004). The relationship that we have established for the distribution of elephants and non-human primates in relation to roads could be applied (Blom, 2001; Blom et al., 2004) to model the density and distribution of these species in similar areas using a Geographical Information System (e.g. Michelmore et. al., 1994).

It appears that human activities negatively influence the distribution of large forest animals in DzangaSangha. There is much evidence of human intrusion into the Park. The highest intensities of human traces were found just inside the Park boundary opposite the village of Bayanga, but traces were also found throughout the Park. Hunting traces were most intensive within $3 \mathrm{~km}$ of secondary roads and this did not vary greatly with distance from Bayanga (Blom, 2001). As these secondary roads (in contrast to the main road) are closed to vehicles this underlines the importance of hunting on foot in this area. Distances from the village and the main road, as well as the distance from secondary roads, appeared to have the greatest influence, affecting half of the species studied.

Elephants in particular were significantly less common in areas used by humans. Together with the location of roads, human trace explained $39 \%$ of their distribution within the National Park. This avoidance behaviour has also been reported in Gabon (Barnes et al., 1991). Several reports indicate that elephants favour habitats, such as light gaps and disturbed forest, where there is abundant ground vegetation (Barnes et al., 1991; White, 1994) but we found no significant correlation with either light gaps or disturbed forest. Light gaps were frequently found near roads, which elephants generally avoid, but disturbed forest was more common deep within the Park. This leads us to believe that elephants find enough herbaceous vegetation and other food resources such as fruit throughout this forest.

Similarly we found no correlation between gorilla encounter rates and habitat, as had been previously reported for this species (Tutin \& Fernandez, 1984, 1993; Carroll, 1997; Doran \& McNeilage, 1998). This could be a result of the time period in which the data were collected, 
being the first 3 months of the rainy season. This is probably the period with the highest fruit availability and fruit consumption by gorillas, when they leave relatively few feeding remains of terrestrial herbaceous vegetation (Remis, 1994; Goldsmith, 1996). However, encounter rates alone should be interpreted cautiously as difference in visibility between habitats could have influenced the data collected. The recent availability of habituated groups of gorillas (in Lossi Reserve near the Odzala National Park, Congo, and in Dzanga-Sangha, including the Ndoki sector of the Dzanga-Ndoki National Park) will permit direct observations. These will provide information on, for example, numbers of nest produced per weaned individual, differences in nests between gorillas and chimpanzees, type of habitat used for nesting, and average number of dung piles produced per day per individual.

The grey-cheeked mangabey was significantly more common where human disturbance (particularly hunting) was low. Both putty-nosed and crowned monkeys were more abundant further away from the village and the main road. The distance from secondary roads influenced the mustached monkey and agile mangabey, but the distance to the main road did not influence them. Possibly they are only negatively influenced by human activity if it is in the form of hunting.

The results of this study show that even though Dzanga-Ndoki is officially a strictly protected area, people make frequent incursions into the Park, significantly affecting the distribution of animals. As secondary roads are used to penetrate into the Park, especially for hunting activities, increasing anti-poaching patrols within $3 \mathrm{~km}$ of roads could be an effective protection measure. Patrolling has taken these findings into account and the number of patrols has almost tripled (D. Greer, pers. comm., March 2005). Poaching pressure appears, however, to have significantly increased since this research was carried out due to an increase in the population of Bayanga (D. Greer, pers. comm., June 2004). The number of snares confiscated, for example, has more then doubled between 1999 and 2004 (D. Greer, pers. comm., March 2005). Whether the apparent increase in observations of poaching is due to increased patrolling remains unclear, however.

\section{Acknowledgements}

This work was made possible through grants from WWF-US and WWF-Germany and the United States Fish and Wildlife Service, as well as student grants from the FONA Foundation, Lucie Burgers Foundation for Comparative Behaviour Research and the Wageningen University Foundation. This research would not have been feasible without the constant support of the DzangaSangha Project and its staff. We would especially like to thank the field team, consisting of the permanent field staff, students, volunteers and all the BaAka trackers. We would like to thank Kate Abernathy, Richard Barnes, Arend Brunsting, Richard Carroll, Chloe Cipolletta, Gerrit Gort, Jefferson Hall, Han Olff, Guy Rondeau, Natasha Shah, Lisa Steel, Alfred Stein, Peter Walsh and Lee White for their assistance and/or useful comments and suggestions. Finally, we would like to thank the WWF staff in Bangui, Washington and Frankfurt for their support.

\section{References}

Barnes, R.F.W., Barnes, K.L., Alers, M.P.T. \& Blom, A. (1991) Man determines the distribution of elephants in the rain forests of northeastern Gabon. African Journal of Ecology, 29, 54-63.

Barnes, R.F.W., Beardsley, K., Michelmore, F., Barnes, K.L., Alers, M.P.T. \& Blom, A. (1997) Estimating forest elephant numbers with dung counts and a geographic information system. Journal of Wildlife Management, 61, 1384-1393.

Blom, A. (1993) List of the Large Mammals of the

Dzanga-Sangha Dense Forest Reserve and the Dzanga-Ndoki National Park. World Wildlife Fund, Bangui, Central African Republic.

Blom, A. (2001) Ecological and economic impacts of gorilla-based tourism in Dzanga-Sangha, Central African Republic. PhD thesis, Wageningen University, Wageningen, The Netherlands.

Blom, A., Almaši, A, Heitkonig, I.M.A., Kpanou, J.-B. \& Prins, H.H.T. (2001) A survey of the apes in the Dzanga-Ndoki National Park, Central African Republic. African Journal of Ecology, 39, 98-105.

Blom, A., van Zalinge, R., Mbea, E., Heitkonig, I.M.A. \& Prins, H.H.T. (2004) Human impact on wildlife populations within a protected central African forest. African Journal of Ecology, 42, 23-31.

Carroll, R.W. (1986a) Status of the lowland gorilla and other wildlife in the Dzanga-Sangha region of southwestern Central African Republic. Primate Conservation, 7, 38-41.

Carroll, R.W. (1986b) The Creation, Development, Protection, and Management of the Dzanga-Sangha Dense Forest Sanctuary and the Dzanga-Ndoki National Park in Southwestern Central Africa Republic. Unpublished Report, Yale University, New Haven, USA.

Carroll, R.W. (1986c) The Status, Distribution, and Density of the Lowland Gorilla (Gorilla gorilla gorilla (Savage \& Wyman)), Forest Elephant (Loxodonta africana cyclotis), and Associated Dense Forest Fauna in Southwestern Central African Republic: Research Towards the Establishment of a Reserve for their Protection. Unpublished Report, Yale University, New Haven, USA.

Carroll, R.W. (1988a) Relative density, range extension, and conservation potential of the lowland gorilla (Gorilla gorilla gorilla) in the Dzanga - Sangha region of southwestern Central African Republic. Mammalia, 52, 309-323.

Carroll, R.W. (1988b) Elephants of the Dzanga-Sangha dense forest of southwestern C.A.R. Pachyderm, 10, 12-15.

Carroll, R.W. (1992) The Development, Protection, and Management of the Dzanga-Sangha Dense Forest Special Reserve and the Dzanga-Ndoki National Park in Southwestern Central African Republic. Dzanga-Sangha Reserve Project and World Wildlife Fund, Washington, DC, USA. 
Carroll, R.W. (1997) Feeding ecology of lowland gorillas (Gorilla gorilla gorilla) in Dzanga-Sangha Reserve of the Central African Republic. PhD thesis, Yale University, New Haven, USA.

Doran, D.M. \& McNeilage, A. (1998) Gorilla ecology and behaviour. Evolutionary Anthropology, 6, 120-131.

Fay, J.M. (1989) Partial completion of a census of the lowland gorilla (Gorilla gorilla gorilla) in the Central African Republic. Mammalia, 53, 203-215.

Fay, J.M. (1991a) An elephant (Loxodonta africana) survey using dung counts in the forests of the Central African Republic. Journal of Tropical Ecology, 7, 25-36.

Fay, J.M. (1991b) Forest elephant populations in the Central African Republic and Congo: the Central African Republic. Pachyderm, 14, 4-12.

Fay, J.M. (1997) The ecology, social organization, populations, habitats and history of the western lowland gorilla (Gorilla gorilla gorilla Savage \& Wyman, 1874). PhD thesis, Washington University, Washington, DC, USA.

Fitzgibbon, C.D., Mogoka, H. \& Fanshawe, J.H. (1995) Subsistence hunting in Arabuko-Sokoke Forest, Kenya and its effects on mammal populations. Conservation Biology, 5, 1116-1126.

Goldsmith, M.L. (1996) Ecological influences on the ranging and grouping behaviour of western lowland gorillas at Bai Hokou, Central African Republic. PhD thesis, State University of New York at Stony Brook, Stony Brook, USA.

Gonda Ngbalet, M. (1995) Données démographique de Dzanga-Sangha. Rapport intermediare. Projet Dzanga-Sangha, Université de Bangui, Bangui, Central African Republic.

Hall, J.S., White, L.J.T., Inogwabini, B.I., Omari, I., Morland, H.S., Williamson, E.A., Walsh, P., Saltonstall, K., Sikubwabo, C., Bonny, D., Kiswele, K.P., Vedder, A. \& Freeman, K. (1998) A survey of Grauer's gorillas (Gorilla gorilla graueri) and chimpanzees (Pan troglodytes schweinfurthi) in the Kahuzi-Biega lowland sector and adjacent forest in eastern Zaire. International Journal of Primatology, 19, 207-235.

Kent, M. \& Coker, P. (1994) Vegetation Description and Analysis: A Practical Approach. John Wiley \& Sons, Chichester, UK.

Lahm, S.A., Barnes, R.F.W., Beardsley, K. \& Cervinka (1998) A method for censusing the greater white-nosed monkey in northeastern Gabon using the population density gradient in relation to roads. Journal of Tropical Ecology, 14, 629-643.

Michelmore, F., Beardsley, K., Barnes, R.F.W. \& Douglas-Hamilton, I. (1994) A model illustrating the changes in forest elephant numbers caused by poaching. African Journal of Ecology, 32, 89-99.

Noss, A.J. (1995) Duikers, cables, and nets: a cultural ecology of hunting in a central African forest. PhD thesis, University of Florida, Gainesville, USA.

Noss, A.J. (1998) The impacts of cable snare hunting on wildlife populations in the forests of the Central African Republic. Conservation Biology, 12, 390-398.
Oates, J.F. (1996) Habitat alterations, hunting and the conservation of folivorous primates in the African forests. Australian Journal of Ecology, 21, 1-19.

Prins, H.H.T. \& Reitsma, J. (1989) Mammalian biomass in an African Equatorial rain forest. Journal of Animal Ecology, 58, 851-861.

Remis, J.M. (1994) Feeding ecology and positional behaviour of western lowland gorillas (Gorilla gorilla gorilla) in the Central African Republic. PhD thesis, Yale University, New Haven, USA.

Sokal, R.R. \& Rohlf, F.J. (1995) Biometry. 3rd edition. W.H. Freeman and Co., New York, USA.

SPSS (1997) SPSS Base 8.0. SPSS Inc., Chicago, USA.

Ter Braak, C.J.F. (1987-1992) CANOCO - A FORTRAN Program for Canonical Community Ordination. Microcomputer Power, Ithaca, USA.

Tutin, C.E.G. \& Fernandez, M. (1984) Nation-wide census of gorilla (Gorilla g. gorilla) and chimpanzee (Pan t. troglodytes) in Gabon. American Journal of Primatology, 6, 313-336.

Tutin, C.E.G. \& Fernandez, M. (1992) Insect eating by sympatric lowland gorillas (Gorilla g. gorilla) and chimpanzees (Pan t. troglodytes) in the Lopé Reserve, Gabon. American Journal of Primatology, 28, 41-48.

Tutin, C.E.G. \& Fernandez, M. (1993) Composition of the diet of chimpanzees and comparisons with that of sympatric lowland gorillas in the Lopé Reserve, Gabon - Composition du régime alimentaire des chimpanzés et comparaison avec celui des gorilles de plaine de la Réserve de la Lopé, Gabon. American Journal of Primatology, 30, 195-211.

White, L.J.T. (1994) Biomass of rainforest mammals in the Lope reserve, Gabon. Journal of Animal Ecology, 63, 499-512.

\section{Biographical sketches}

Allard Blom's recent research concentrates on effective management and monitoring of protected areas and their longterm financing. He recently left central Africa, after almost 20 years there, to join WWF in Washington, DC.

Robert van Zalinge conducted surveys in Dzanga-Sangha, and recently studied deforestation in Malaysia and worked on mangrove conservation in Bangladesh.

Ignas Heitkönig has experience in west and southern Africa, including land-use analysis, large herbivore ecology, and human-wildlife conflicts.

Herbert Prins has extensive research interests in tropical ecology and conservation. 